\title{
Investigation of Frequent Failure of Francis Hydraulic Turbine Guide- Vane Shear Pin of Shiroro Hydro-Electric Power Station
}

\author{
M. A. Bawa ${ }^{a^{*}}$, A. Tokan ${ }^{b}$ and I. Salisu ${ }^{\mathrm{c}}$ \\ ${ }^{\mathrm{a}, \mathrm{b}}$ Department of Mechanical/Production Engineering, Abubakar Tafawa Balewa University, Bauchi, Nigeria. \\ Shiroro Hydro-Electric Power Generation Station, Kainji, Nigeria.
}

Corresponding Author: M. A. Bawa (mabawa@atbu.edu.ng;+2348063226489)

\begin{abstract}
Francis Hydraulic Turbine Guide-vane shear pin is a mechanical sacrificial component designed to break when the mechanical overload arises to prevent severe damage of guide-vane, which is an expensive component in the turbine assembly of hydro-power station. The pin is expected to serve for a minimum period of 10 years under normal working condition before failure occurs as obtained in most hydro-electric power stations globally. The shear pins in Shiroro hydro-electric power generation station located in Niger state of Nigeria were found to be frequently failing within a year of operation before reaching its predetermined load. This research investigated the possible causes of the frequent failure of the shear pins with a view to proffer solution. Analyses of the existing shear pin with respect to material specifications, micro-structural analysis using spectrophotometer where both visual and scanning electrode microscopy (SEM) was done in addition to mechanical tests to ascertain conformity with standards. The results showed that the shear pin material conforms to the ASTM 420, which is the standard for production of the shear pin. The SEM results shows that the failure of the shear pins was due to low cyclic fatigue growth attributed to the effect of intermittent and unsteady operations of the turbine. The visual examination revealed no defect on the phases of the material indicating that the fractured failure was not due to any form of inconsistency resulting from segregation or related effects. The mechanical test revealed yield strength of $600 \mathrm{~N} / \mathrm{mm}^{2}$, ultimate tensile strength of 750 $\mathrm{N} / \mathrm{mm}^{2}$ and hardness of $29 \mathrm{HRC}$ which agreed with standard specifications for the shear pin. The results indicated that the frequent failure of shear pins could be as a result of other sources other than material specifications.
\end{abstract}

Keywords: Guide-Vane, Hydraulic Turbine, Hydro-Electric Power, Shear Pin, Micro-Structure, Scanning Electrode Microscopy, Mechanical Tests, Cyclic Fatigue, Segregation.

\section{INTRODUCTION}

Shiroro Hydro-Electric Power Station is the first and major source of electricity in Nigeria with its source of water from a confluence of River Kaduna and River Dinya in Niger state of the federation. The station has an installed capacity of 600MW from four (4) generating units rated at 150MW each at a head level of 97m (Gbadamosi et al., 2015). Each unit comprises of a vertical Francis Hydraulic Turbine controlled by an Electro-Hydraulic Governor System (Addulazzeez and Musa, 2000). The turbine is secured by a shear pin that act as a mechanical sacrificial component designed to break itself when a mechanical overload arises in order to prevent damage of the guide-vane/wicket gate that is one of the critical and expensive components in the turbine assembly (Kim et al., 2009; Sankar et al., 2011). These shear pins are expected to last minimum of eight years of continues in operational service before replacement to ensure uninterrupted power supply. However, in Shiroro hydro-electric power station, the shear pins frequently failed before reaching its predetermined load and service life. This research investigated the possible causes of the frequent failure of the Francis hydraulic turbine guide-vane shear pin in Shiroro hydro-electric power station by studying the material and mechanical properties of the existing shear pin used in the station in comparison to standards with a view to proffer solution in order to avoid frequent shut down which usually has adverse effect to the economy of Nigeria as most industries rely on the station for power. Initially, the at preliminary services, the shear pins were capable of sustaining the operations of the station as expected but later started to fail prematurely resulting to unstable power supply due to maintenance. Table 1 shows the record of shiroro hydro-electric power station with respect to shear pins replacement. From the table, it can be seen that the time required to replace failed shear pins is much in comparison to the consumer demand. Researchers have worked on similar shear pins failures in applications involving turbines with promising results. Sankar et al (2011) investigated the failure of shear pins in wind turbine generator and found out that the cause was as a result of misalignment between the driving and driven element that led to low cyclic fatigue failure. Budiman et al., (2016) studied and analyzed the design of a fail-safe mechanism for a guide vane of a hydro turbine under various loading conditions and concluded on the need to alter the initial design. Frunzăverde et al., (2010) presented the failure analysis of a broken Francis turbine runner blade with suggestion of material and design modifications. Abhay et al (2008) studied the metallurgical effects on a Failed EN 19 steel shear pin and recommend special considerations on the design of shear pins due to the critical role they played in industrial applications. Subramonian and Alif (2012) did critical review of electro-mechanical door locking systems and proposed the development of energy saving door locking system that could avoid unnecessary energy wasting as experienced in industries similar to shiroro hydro-electric power stations. Yousef and Safar (2010) reported the effectd of part loads on guide vane mechism of Agnew micro hydro-turbine with suggestion on design and material modification to improve the efficiency of the turbine. Many research works have been published on 
failure analysis of similar systems such as Kaplan turbine, steam generators and air compressors. To investigate the causes of the frequent failure of the shear pin in Shiroro hydro-electric power station, the material and mechanical properties of the existing shear pin was studied alongside the failed pin. Analyses was done with respect to material specifications, micro-structure and mechanical properties by the use of spectrophotometer involving both visual and scanning electrode microscopy (SEM) and mechanical testing devices. Figure 1 shows the arrangement of shear pin with Turbine regulatory ring, typical as received shear pin and failed shear pin as used in Shiroro hydro-electric power station. Figure 2 shows the operating principles of typical Francis Turbine Hydraulic Guide-Vane showing the gates arms keyed to the stem above the upper bearing of the gate which is connected to the shift ring by links having a shear pin or breaking section designed to break if some obstruction prevents the gate from moving push-pull rods to the servomotors that connects the shift ring (Kim et al., 2009).
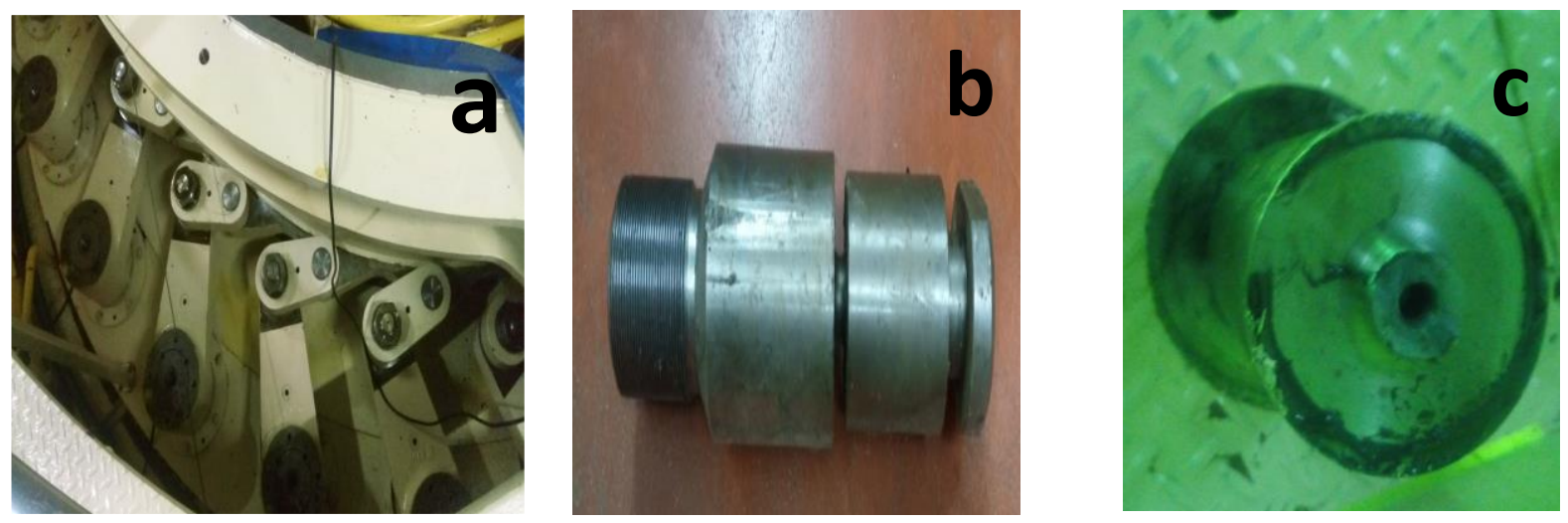

Figure 1: (a) Arrangement of Shear Pin with Turbine Regulatory Ring, (b) Shear Pin and (c) Fractured Shear Pin

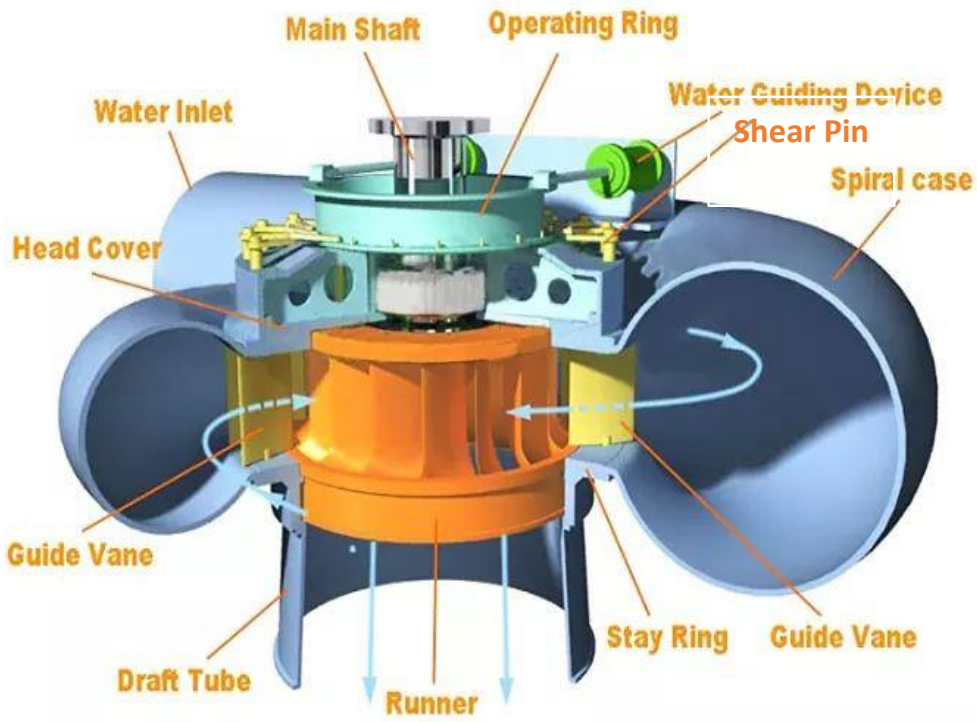

Figure 2. The Arrangement of Francis Turbine Guide-Vane Components (Geller and Menses, 2020)

\subsection{METHODOLOGY}

To determine the possible cause of the frequent and unusual failure of the shear pin of the turbine guide-vane of the Shiroro hydro-electric power station, material and mechanical properties were investigated to find out conformity or otherwise of the shear pin with respect to stipulated standards. This was done to determine any imperfection in the shear pin composition and possible defects by adopting the following methods;

\subsection{Mechanical Tests}

Tests were conducted on the shear pins on Universal and hardness testing machines to determine hardness, yield strength and ultimate tensile strength to ascertain conformity with standard. The result is as shown in Table 2. 
Table 1. Shear Pin Failure History of Shiroro Hydro-Electric Power Station

\begin{tabular}{lcc}
\hline $\begin{array}{l}\text { Commissioning } \\
\text { Date of the Units } \\
\text { in SHEPS }\end{array}$ & $\begin{array}{l}\text { Date of Shear-Pin } \\
\text { Failure }\end{array}$ & $\begin{array}{l}\text { Time Taken in } \\
\text { Hours for Shear } \\
\text { Pin } \\
\text { Replacement }\end{array}$ \\
\hline Unit 411G1 & $06-10-2015$ & 7 \\
20-06-1991 & $16-06-2017$ & 4 \\
& $20-06-2018$ & 5 \\
Unit 411G2 & $02-01-2010$ & 12 \\
20-06-1991 & $15-02-2016$ & 5 \\
& $06-03-2017$ & 4 \\
Unit 411G3 & $17-03-2011$ & 4 \\
20-06-1991 & $04-04-2012$ & 4 \\
& $07-04-2019$ & 5 \\
Unit 411G4 & $10-04-2016$ & 7 \\
20-06-1991 & $16-06-2017$ & 5 \\
& $20-08-2019$ & 4 \\
\hline
\end{tabular}

\subsection{Spectrometric Analysis}

The material composition of shear pin was investigated for any imperfection or deviation from the standard using absorption spectrophotometric analysis method which is based on the principles of atomic physics whereby an atom emits or absorbs light of a certain wavelength within the ultraviolet and visible region of the energy spectrum when there is an upset in the energy balance within its atomic structure. Spectrometric analysis method for samples of the failed shear pin was used to determine the quantity and percentage weight of the alloying elements. The prepared sample was digested before being subjected to an oxy-acetylene flame used to atomize the metallic elements in the atomic absorption spectrometry. The outcome of the spectrometric analysis is as shown in Table 3.

\subsection{Microscopic Analysis}

The microscopic analysis of the failed shear-pin was carried using metallography and fractography.

\subsubsection{Metallography}

Sample was of the failed shear pin was prepared for metallography by mounting it on the machine for rough, intermediate and fine polishing using different grits silicon carbide abrasive clothes. The sample was etched using nital-solution in order to expose the grain boundaries for proper and ease of examination and interpretations. Microstructures of the damaged portions of the two halves of the fractured shear pins samples were analyzed for micro cracks and its history from initiation to termination using optical microscope as well as scan electron microscope (SEM). Metal power Image analyzer was used in the study of the microstructure of the specimens at $\mathrm{X} 200,50 \mu \mathrm{m}$ magnification factor.

\subsubsection{Fractography}

The fractured surface of the failed shear pin was analyzed using fractographic methods which are routinely used to determine the cause of failure in engineering structures, especially in product failure and the practice of forensic engineering or engineering failure analysis. It was done to determine the cause of failure of the shear pin by studying the characteristics of the fractured surface. The surface of the fractured shear pins was cleaned ultrasonically in acetone and examined at different magnification scale using SEM with accelerating voltage of $25 \mathrm{kV}$ (ASM-H, 1992).

\subsection{RESULTS AND DISCUSSIONS}

The results after the experimental procedures are as follows; 


\subsection{Mechanical tests on shear pin material}

Table 1 shows the results of mechanical properties test conducted on the shiroro hydro-electric power station carried out on universal tensile machine and hardness testing machine. From the results obtained, the yield strength, ultimate tensile strength and hardness values revealed that these values fall within stipulated standard for production of shear pin and general turbin and its components. These results indicates that the frequent failure of the shiroro hydro-electric power was not as a result of deficiencies in materials specifications as the measured mechanical properties shows that the shear pins material fits closely to that of ASTM 420 unique special steel that has very good mechanical properties combined with extraordinary good machinability recommended for production of the pins.

\subsection{Spectrometric analysis}

The chemical analysis of the failed shear pin material was carried out by spectrophotometer and the results are presented in Table 3. It is observed from the Table that the composition of failed shear pin conform with the specifications of ASTM 420 material recommended for production of shear pins for turbine guide vane. It therefore suggests that the shear pin frequent failure is not as a result of compositional effect.

\subsection{Microscopic analysis}

The microspcopic analysis of the shear pin material was done with a view to checking phase stability and uniformity as well as chemical contents using metallography and fractography.

Table 2. Results of Mechanical Properties of the Shear Pin

\begin{tabular}{ll}
\hline Material properties & Values \\
\hline Elastic modulus $(\mathrm{MPa})$ & 215000 \\
Ultimate tensile strength $\left(\mathrm{N} / \mathrm{mm}^{2}\right)$ & 750 \\
Hardness (HRC) & 29 \\
Poisson's ratio & $0.28 \sim 0.299$ \\
Shear modulus (GPa) & 79000 \\
Yield strength $\left(\mathrm{N} / \mathrm{mm}^{2}\right)$ & $600(\max .800)$ \\
\hline
\end{tabular}

Table 3: Result of the Spectrometric Analysis of the Shear Pin Material

\begin{tabular}{lll}
\hline Element & $\begin{array}{l}\text { Specification of } \\
\text { ASTM 420 steel } \\
(\text { wt. \%) }\end{array}$ & $\begin{array}{l}\text { Composition } \\
\text { of the failed } \\
\text { shear pin } \\
\text { (wt. \%) }\end{array}$ \\
\hline $\mathrm{Fe}$ & Remaining & 83.3 \\
$\mathrm{Cr}$ & $12-14$ & 13.5 \\
$\mathrm{Si}$ & 1.0 (max.) & 1.0 \\
$\mathrm{C}$ & $0.16-0.25$ & 0.25 \\
$\mathrm{P}$ & 0.04 (max.) & 0.015 \\
$\mathrm{~S}$ & 0.03 (max.) & 0.015 \\
$\mathrm{Mn}$ & 1.50 (max.) & 1.50 \\
\hline
\end{tabular}

\subsubsection{Metallography}

Metallographic examinations on some selected failed shear pins shows uniformity and close resemblance in their microstructures that are hardly distinguishable as shown in Figure 3. This inferred that the frequent failure of the shear pins could not have been due to discontinuity or segregations in the phases. The microstructure revealed dispassion of ferrite, retained austenite and traces of tempered martensite. The results indicated that the shear pin material was tempered after the preliminary manufacturing stage to impart some properties that will ensure durability of the pins as specified in the requirements for the shear pin production.

\subsubsection{Fractography}

Figures 4 and 5 shows the result of fractography of the failed shear pin of the Shiroro hydro-electric power station done with $25 \mathrm{kV}$ accelerating voltage applied for the SEM analysis. From the figure, Micro cracks and oxide 
particles were seen on the surface of the fractured shear pin which could most likely be due to overload or low cyclic fatigue phenomenon likely to be caused by the station's operating condition with frequent load rejection that causes water hammer or similar effects (Suresh, 1998; Blazek, 2001; Schijve, 2001; Kumar et al., 2012; Shalak, 2019). Visual observation and the fractographic analysis showed that the fracture was initiated on machining marks along the surface of the shear pin near the neck.
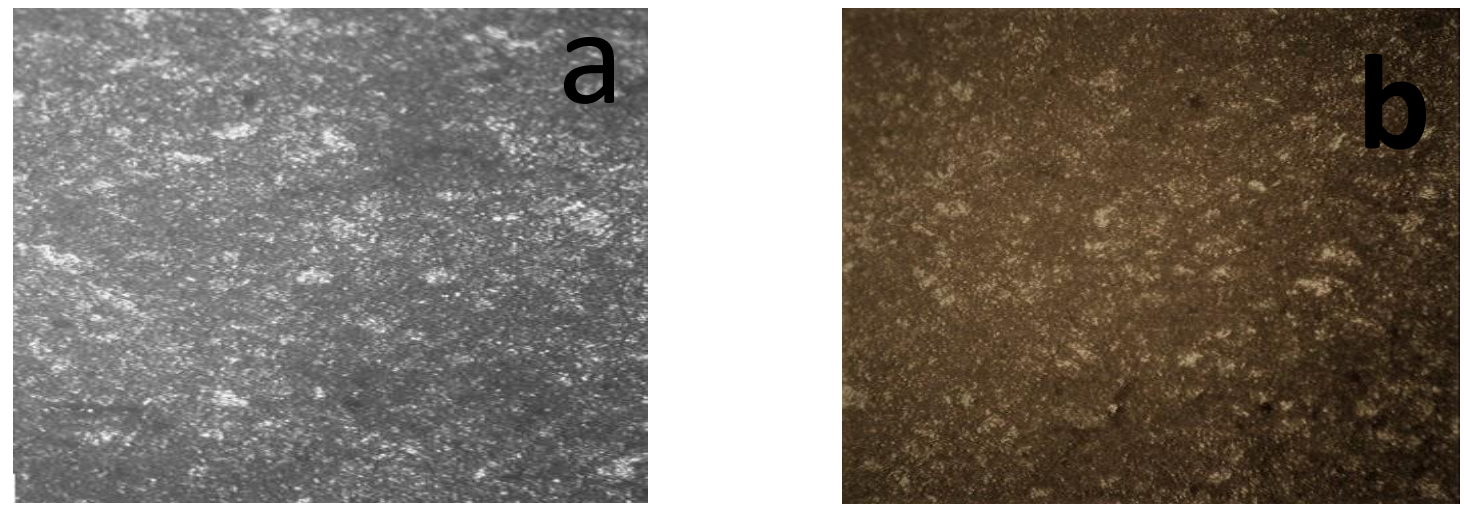

Figure 3: Microstructure of Two Samples of Shear Pin Material Showing (a) Ferrite and (b) Tempered Martensite Structure

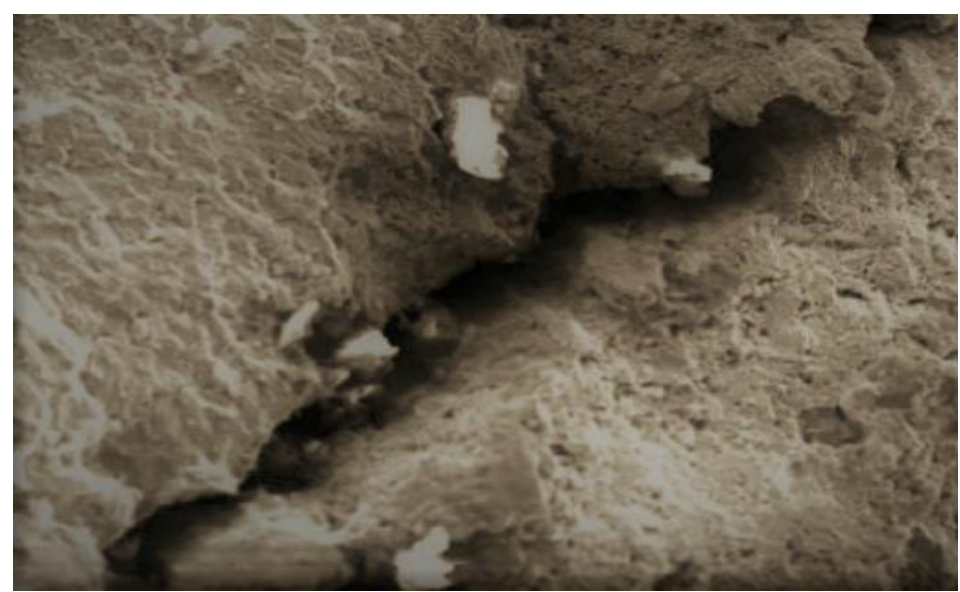

Figure 4: Result of Fractography of a failed shear pin taken with 25 kv @ X200 magnification factor

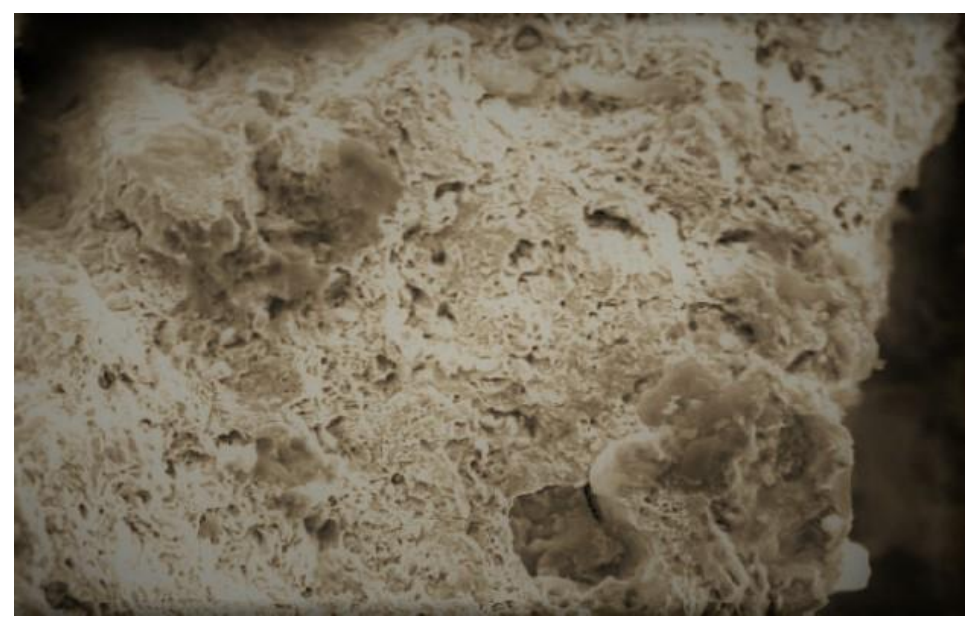

Figure 5: SEM at $25 \mathrm{kv}$ Fractograph at the Neck Portion Showing Brittle Fracture at X200 Magnification Factor 


\subsection{CONCLUSION}

The shear pin material was investigated for any imperfection and material defect. The results indicated that the shear pins are made of ASTM 420 steel that has very good mechanical properties combine with machinability. The results of the chemical analysis showed that the shear pin material is in accordance with ASTM 420 specifications which is the standard for making hydro-turbine parts. The visual observation and the microfractographic examination confirmed that the fracture was nucleated near the neck region of the shear pin which suggests that the failure of the shear pin is most likely due to the water hammer which generate low cyclic fatigue load until failure occurred. From the results obtained, the frequent failure of the shear pin cannot be attributed to the mechanical properties and chemical composition of the material. The metallographic analyses revealed that the failure is not related to any defect in the material phases or with any abnormal conditions like segregations or unusual grain sizes and arrangements.

It is therefore recommended that frequent failure of the shear pins of Shiroro Hydro-Electric Power Station could be avoided or drastically reduced by adopting the following;

i) Adopting spinning reserve system not free governor system for operating Francis Hydraulic turbine.

ii) Improving the transmission and distribution network so that the power generated can be evacuated without rejection.

iii) Further analysis on the shear pin frequent failure be carried out based on design and applied forces.

iv) Analysis of pressure effects at different points in the penstock, wave speed of water hammer and guide-vane closing time (wicket gate) be carried out to mitigate the effect of water hammer.

\section{Acknowledgement}

The authors are grateful to the Management of Abubakar Tafawa Balewa University Bauchi, Nigeria and that of Shiroro Hydro-Electric Power Station, Niger State, Nigeria for providing enabling condition and support through out this research work.

\section{References}

1. Abhay, K. J., Sreekumar, K. \& Mittal, M. C., 2008. Metallurgical Studies on a Failed EN 19 Steel Shear Pin. Engineering Failure Analysis, 15, 922-930.

2. Addulazzeez, D. and Musa, A., 2000. Upgrading of Generating Units Referenced to Shiroro Hydro-Electric Power Station. Paper presented at the meeting of the Nigerian Society of Engineers on Challenges and Prospect of Hydro Power Generation in Nigeria, Shiroro, Niger state, Nigeria.

3. ASM-H, 1992. ASM Hand Book Committee: Alloy Phase Diagram. ASM Hand Book, (ed. 10a), Vol. 3. ASM International Metal park, Ohio, USA.

4. Blazek, J., 2001. Computational Fluid Dynamic: Principles and Applications. Oxford, Elsevier Publishing

5. Budiman, B. A., Suharto, D., Indra, D., Muhammed, A. \& Juangsa, F. B., 2016. Fail-Safe Design and Analysis for the Guide Vane of a Hydro Turbine. Advances in Mechanical Engineering, 8(7), 1-8.

6. Frunzăverde D., Muntean S., Mărginean G., Câmpian V., Marşavina L., Terzi R., and Şerban V., 2010. Failure analysis of a Francis turbine runner. 25th IAHR Symposium on Hydraulic Machinery and Systems Earth and Environmental Science, 12 (10), 12-115.

7. Gbadamosi, S.L., Ojo O., Adedayo, A. \& Nnaa, L., 2015. Evaluation of Operational Efficiency of Shiroro Hydro-Electric Plant in Nigeria. International Journal of Science and Engineering Investigations. 4, (42).

8. Geller, M. T. B. \& Meneses, A. D. M., 2020. Life Cycle Assessment of a Small Hydropower Plant in the Brazilian Amazon. Journal of Sustainable Development of Energy, Water and Environment System, 4, (4). 379-391

9. Kim, C., Sood, V. K., Jang, G., Lim, S. \& Lee, S. 2009). HVDC Transmission: Power Conversion Applications in Power Systes. John Wiley and Sons (Asia) Pte Ltd. Singapore

10. Kumar, C. S., Kimambo, C. Z. \& Nielsen, T. K. (2012). Hydropower in the context of sustainable energy supply: A review of Technology and Challenges. International Scholarly Research Notice, Hindawi. Article ID 730631

11. Sankar, S., Nataraj, M., Prabu, V. R. 2011. Failure analysis of shear pin in wind turbine. Engineering Failure Analysis. 18, 325-339, Elsevier.

12. Schijve, J. (2001). Fatigue of Structures and Materials. Dordrecht: Kluwer Academic Publications.

13. Skalak, R. (2019). An extension of the Theory of Water Hammer. New York: Columbia University.

14. Subramonian, S. \& Alif, A. (2012).Critical Review of Electro-Mechanical Door Locking System and Proposal Towards Development of Innovative Super Energy Saving Door Locking System. International Journal of Engineering Innovative Technology, 2, 201-207.

15. Suresh, S. (1998). Fatigue of Structure and Materials. Cambridge: Cambridge University Press, (2nd edition).

16. Yousef, Y. \& Safar, H. (2010). Improvement of the Efficiency of the Agnew Micro Hydro Turbine at Part Loads due to Installing Guide Vanes Mechanism. Energy Conservation Management; 51, 1970-1975. 